\title{
Partidos y política en Argentina: reflexiones sobre'una relación compleja
}

\author{
Aníbal Viguera
}

FLACSO-MÍXXICO

\begin{abstract}
El desenvolvimiento histórico de los partidos en el sistema político argentino y sus cambios desde el inicio de la redemocratización de 1983 son el tema de este ensayo. Dos dimensiones evalúan este desempeño: la relevancia de las cuestiones relacionadas con "la política" y la organización de las "políticas estatales". Si bien han sido centrales en la primera, en la segunda no han constituido espacios para decisiones políticas. Ello es hoy su principal debilidad.
\end{abstract}

$\mathrm{E}$

n un país como la Argentina, donde la inestabilidad del sistema político ha sido crónica hasta comienzos de la década de los ochenta, resulta tentador sostener que los partidos políticos no han tenido un papel relevante, $o$ han sido muy débiles frente a otros mecanismos de representación y gestión política. Si bien en algún sentido este tipo de afirmaciones podría resultar pertinente, un análisis del papel desempeñado históricamente por ellos dentro del sistema político, y una evaluación acerca de los alcances y limitaciones de su desempeño, requiere de una mayor complejización y de la puntualización de ciertos matices importantes. Este trabajo se propone presentar algunas reflexiones en esa dirección; el análisis realizado nos permitirá además visualizar el alcance y sentido de los cambios que se estarían verificando al respecto a pärtir de la redemocratización iniciada en 1983, y los desafios que presenta actualmente el sistema de partidos en Argentina.

Nuestro punto de partida radica en la idea de que el análisis del funcionamiento de los partidos en el marco del sistema político argentino requiere diferenciar dos dimensiones distintas. 
Por un lado, cabe explorar en qué medida, y de qué manera, los partidos han sido relevantes en cuanto a las cuestiones relacionadas con "la política" en sus términos más generales, es decir, en relación con la conformación y funcionamiento del orden político mismo. Por el otro, debe considerarse qué papel han desempeñado en términos de los mecanismos de elaboración y gestión de "las políticas" generadas en el ámbito del Estado. Si bien ambas dimensiones, que sólo distinguimos aquí analíticamente, se influyen y condicionan en forma recíproca, su diferenciación permite observar aspectos distintos del funcionamiento de los partidos en el marco del sistema político. La medida y el sentido en que pueda afirmarse que los partidos "han funcionado o no" en Argentina depende precisamente de la dimensión que se esté considerañdo.

\section{LOS PARTIDOS Y LA POLÍTICA}

En cuanto a esta primera dimensión, cabría decir que los partidos políticos, sus caracteristicas y las alternativas históricas de su acción, han sido un factor central en la dinámica de funcionamiento del sistema político en su conjunto, aun considerando que durante muchos años las instituciones democráticas no tuvieron vigencia. Esto requiere, a su vez, observar dos aspectos distintos.

Si miramos la cuestión desde el punto de vista de los partidos como unidades, en tanto fuerzas políticas consolidadas en su articulación con la sociedad civil, y atendiendo a la exis- tencia o no de vínculos duraderos entre ellos y la sociedad, resulta evidente que su arraigo e importancia han sido considerables. En efecto, con la consolidación del radicalismo primero y del peronismo después, se constituyeron en Argentina dos partidos fundamentales que han conservado una larga vigencia en el tiempo, reproduciendo sendas subculturas políticas relativamente fuertes, con perfiles definidos que en buena medida funcionaban como núcleos aglutinadores de diversos intereses, valores y demandas de la sociedad civil. Entre las décadas de 1950 y 1980 fueron ellos los que canalizaron las adhesiones políticas ciudadanas en los periodos en que el sistema político se mantuvo abierto al funcionamiento de las instituciones representativas; pero ellos fueron también, explícita o implícitamente, interlocutores estables durante los gobiernos militares. ${ }^{l}$

Esta presencia estable de dos partidos fuertes capaces de concitar de manera permanente la identificación con ellos de diversos sectores sociales, era sin duda un elemento imprescindible para el eventual funcionamiento de los mismos en términos del segundo aspecto que importa considerar aquí, y que es el de su articulación en un sistema de partidos. Dos condiciones esenciales para ello estaban, en este sentido, estructuralmen-

1 Ista caracteristica resalta claramente si la pensamos en contraste con un caso como cl de Brasil, donde no ha existido, históricamente, un sistema partidario basado en unidades importantes que mantuvieran una vigencia temporal semejante a la que venimos scñalando. Sobre cste punto, véasc Mainwaring, Brazilian, 1990. 


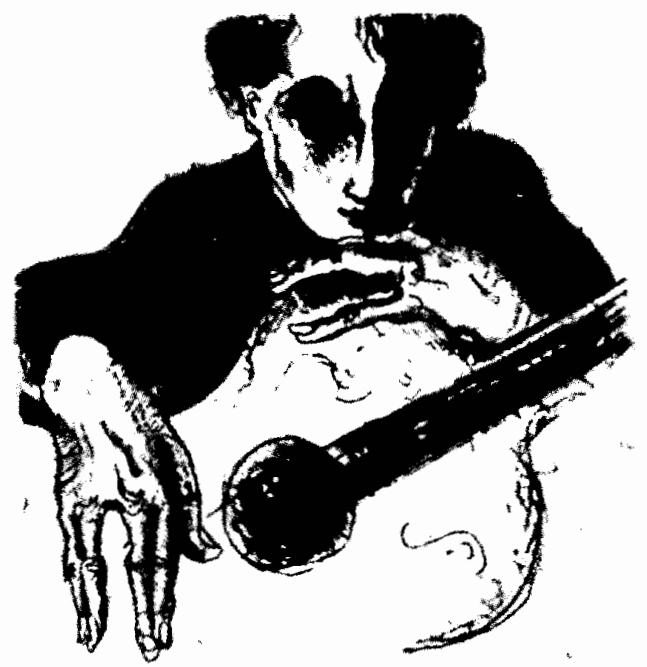

[5S

te dadas: cierta estabilidad en los comportamientos políticos alrededor de un núcleo constante de fuerzas políticas, y el hecho de que éstas funcionaran como alternativas viables $y$ claramente diferenciadas ante la sociedad como para permitir un juego de alternancia entre ellas. Sin embargo, la peculiar modalidad en que las identidades partidarias se constituyeron, y ciertos rasgos recurrentes del comportamiento efectivo de los partidos principales, contribuyeron, junto con otros aspectos del sistema político en su conjunto, a hacer imposible una tercera condición que hubiera resultado imprescindible para que el sistema de partidos operara como tal: la constitución efectiva de los mismos en una suerte de mercado político que implicara reglas aceptadas de intercambio y fundamentalmente la aceptación mutua del otro o de los otros como oposición legítima y alternativa válida de poder. Conservadores y radicales, desde principios de siglo, y sobre todo radicalismo y justicialismo desde los años cuarenta, se involucraron históricamente, en cambio, en un juego de exclusión recíproca en el que en buena medida, la propia identidad partidaria llevaba implicita la negación a aceptar al adversario como opción legítima dentro del sistema político. ${ }^{2}$

Partidos arraigados fuertemente en la sociedad en tanto alternativas polí-

2 Véase Cavarozzi, "Esqucma", 1989) y 1)c Riz, "Política", 1989. 
ticas, entonces, no contribuyeron, debido a su comportamiento histórico específico, a la posibilidad de que el sistema de partidos fuera el eje fundamental de la gestión del poder politico. Pero este dato, unido a los rasgos antes señalados, habla nuevamente de la centralidad que los mismos tuvieron dentro del sistema político en términos de esta primera dimensión que estamos considerando, en tanto no fueron víctimas pasivas de la alteración recurrente del sistema institucional sino fuerzas que activamente, $y$ a partir justamente de su arraigo en la sociedad, operaron en favor de la misma. No es la ausencia de partidos, ni su debilidad, sino la peculiar modalidad de su constitución y relación recíproca, la que permite dar cuenta de su fracaso. "La política", en este sentido, estuvo permeada históricamente por el accionar de los dos partidos fundamentales; buena parte de las alternativas del sistema político, aun durante los periodos autoritarios, pasó efectivamente por ellos. Lo paradójico de todo esto es, sin embargo, que la exclusión mutua entre las dos grandes fuerzas partidarias no estuvo basada en una fuerte oposición programática en torno a los rasgos centrales de las políticas gubernamentales: fue precisamente en relación con "las políticas" que los partidos carecieron de centralidad en el funcionamiento del sistema político argentino.

\section{LOS PARTIDOS Y IAS POIÍTICAS}

En efecto, una perspectiva histórica de mediano plazo permite observar que los partidos no constituyeron, en Argentina, ámbitos importantes en la elaboración y puesta en marcha de las decisiones públicas acerca de políticas, fueran éstas globales o específicas. Pero esto no se debe sólo a que gobernaron durante periodos relativamente breves recurrentemente interrumpidos por golpes militares, lo cual ciertamente contribuyó a obstaculizar su constitución en arenas permanentes y estables de negociación y articulación de políticas. En términos más generales, en Argentina fue particularmente agudo el arraigo de lo que se ha denominado "matriz Estado-céntrica" de relaciones entre Estado y sociedad: ${ }^{3}$ ella supuso, entre otras cosas, una "fórmula política" en la cual el aparato del Estado era la arena privilegiada a la que se dirigían las demandas de los diversos actores por canales aislados entre sí; a su vez, aquél respondía a esas demandas a través de mecanismos fiscales y de manera discrecional y acumulativa, con una direccionalidad inestable y cambiante que tendia a satisfacer alternativamente los reclamos particularistas de los distintos actores privados. Como en otros países, esto significó que la inflación fuera el principal mecanismo "político" a través del cual se dirimían temporaria e inestablemente los conflictos entre sectores en torno a las políticas especificas. ${ }^{i}$ Este patrón de comportamiento, agudizado por la particular intensidad del conflicto distributivo y los altos niveles de confrontación entre los ac-

\footnotetext{
3 Véasc Cavarozzi, "Polítics", 1989.

4 Hirschman, "Matri\%", 1984.
} 
tores, anclados en un sistema político con fuerte peso de los intereses organizados corporativamente, se reprodujo tanto durante los gobiernos democráticos como militares, ${ }^{5}$ sin que los partidos se constituyeran en arenas de agregación y negociación de demandas sectoriales y en la consiguiente posibilidad de articular proyectos comunes negociados entre actores diversos en torno a las políticas fundamentales a adoptar desde el Estado. Los actores corporativos, sobre todo los empresarios, actuaron siempre por fuera de los partidos a través de toda una serie de mecanismos formales e informales de relación con el aparato administrativo, o bien apelaron unilateralmente a aquéllos como otro ámbito de presión en el cual buscar influir en favor de determinadas decisiones. ${ }^{6}$ La estrecha relación de las principales organizaciones sindicales con el peronismo no implicó sino la reproducción de estas tendencias, ya que no estuvo asociada a la consecución efectiva de "coaliciones" con actores empresariales en torno a políticas; la "concertación", cuando fue intentada, fracasó recurrentemente. $^{7}$

5 Véasc, cntrc otros, Acuña, "Organizaciones", 1992.

${ }^{6}$ Apclando ajnat ilustrativa expresión de Morlino, puede decirse que los partidos en Argentina no cjercicron la función de gatekeeping o control del acceso dirccto de los grupos de interés a los ámbitos de toma de decisiones. Véasc Morlino, "Partidos", 1992.

7 las interpretaciones clásicats del peronismo como una "alianza de clases" contre clasc obrera y empresariado industrial no pucelen sostencerse frente a la evidencia del predominio de los comportamicntos sectoriales antes seña-
La fuerte identidad de los partidos fundamentales, entonces, estuvo históricamente mucho más asentada en divergencias ideológico-políticas y simbólicas que implicaban la imposibilidad de aceptar el gobierno del otro, que en diferencias programáticas profundas en torno a las políticas estatales. La lucha entre los partidos en la esfera de "la política" no tendió a vincularse a la disputa o negociación sobre "las políticas", dejando como legado una clara disociación entre ambas dimensiones que puede convertirse hoy en el principal obstáculo para la persistencia del sistema de partidos.

\section{LOS DIIJMAS ACTUALES}

A partir de 1983, la nueva etapa democrática ha estado acompañada de cambios importantes en el funcionamiento del sistema político, que incluyen ciertas modificaciones en cuanto al comportamiento histórico de los partidos fundamentales. En efecto, en el lapso transcurrido desde entonces parece haberse consolidado una nueva modalidad de relación entre las fuerzas partidarias que les ha permitido, ahora sí, funcionar adecuadamente como "sistema de partidos" en torno a las cuestiones más generales de "la política". En este sentido, la superación de la herencia histórica de no aceptación mutua de los partidos co-

lados. Para un análisis concreto de dichos patrones de comportamiento en el tereer gohicrno del Justicialismo (1973-1976) véasc 1)e Ri\%, Retomo, 1981. Sobre el facaso permanente de los intentos de concertación, véasc Cavarorzi, 1)c Ri\% y Fildman, "Contexto", 1987. 
mo actores legítimos es un dato central de la última década, y ha contribuido sin duda a sentar las bases para una estabilidad institucional que ha adquirido progresivamente visos de una inédita solidez.

Sin embargo, la histórica disociación entre los partidos, y la negociación y articulación de políticas, sigue en pie, y es aquí donde pueden empezar a aparecer tensiones importantes en cuanto al funcionamiento del sistema político. En este aspecto la debilidad de la tradición y de las prácticas mismas de concertación y de articulación de demandas a través de los partidos contribuye a acentuar el carácter hoy fuertemente centralizado y tecnocrático de la toma de decisiones respecto a las políticas públicas fundamentales. Si bien es cierto que esto ha significado fuertes niveles de "gobernabilidad", entendida como eficacia decisional, a mediano plazo ello puede operar negativamente si se observa la gobernabilidad desde una perspectiva más amplia. Si en los 50 años previos a la etapa actual lo problemático fue, como vimos, la manera mutuamente excluyente en que los partidos reproducían un alto grado de representatividad respecto a vastos sectores de la población, hoy el problema puede empezar a ser el opuesto. Diluida la identidad partidaria basada en la tajante oposición con el adversario, en efecto, ella no ha sido reemplazada por la constitución de los partidos en alternativas programáticas claramente diferenciadas; para ello, cabe decir, resulta fundamental que la política partidaria se articule efectivamente a la propuesta y esta- blecimiento de las decisiones sobre políticas, pasando a expresar proyectos alternativos en ese sentido. El aislamiento de las esferas de toma de decisiones respecto de los partidos puede desembocar ahora en un vaciamiento progresivo de lo que constituyó una de las bases de la fortaleza de los partidos en el pasado, es decir su fuerte arraigo en la sociedad en tanto unidades que canalizaban preferencias ciudadanas en torno a la política. La persistencia de una largamente arraigada escisión entre representatividad política -encarnada exitosamente por los partidos- y decisiones sobre políticas públicas es quizá hoy el dilema más importante que enfrenta el sistema político si se trata de afianzar pautas estables de funcionamiento institucional en las que el sistema de partidos sea el eje efectivo del sistema de gobierno.

Por otra parte, si cabe introducir una perspectiva algo más normativa, la posibilidad de que los partidos funcionen como canales de articulación y negociación de demandas en torno a políticas, puede asumirse como condición necesaria para que éstas tiendan a superar, de manera estable y duradera, las viejas prácticas sectoriales y particularistas propias de la matriz Estado-céntrica, para poder favorecer la consecución de metas globales que integren a los distintos sectores de la sociedad.

Como adelantamos al comienzo, una evaluación acerca de si el sistema de partidos "funciona" o no en Argentina requiere de la distinción analítica entre las esferas de la politica y las políticas; ello permite sugerir que el 
desafio de la hora actual parece ser, en ese sentido, el de superar la histórica disociación entre ambas.

\section{BIBLIOGRAFIA}

- $\Lambda$ cuña, Carlos, "Organizaciones emprcsariales y políticas públicas en $\Lambda$ rgentina", en Varios autores, Organizaciones empresariales y políticas públicas, CIESU-FESUR, 1992.

- Cavarozzi, Marcelo, "El esquema partidario argentino: partidos vicjos, sistema débil", en Marcelo Cavarołzi y Manuel $\Lambda \mathrm{n}$ tonio Garreton (coords.), Muerle y resurrección. Los partidos políticos en el auloritarismo y las transiciones del Cono Sur, FLACso, Santiago, 1989.

- "Politics? a key for the long term in South America", en William Smith, Carlos Acuña y Tiduardo Gamiarra (cds.), Latin american political economy in the age of neoliberal reform, theoretical and comparative perspectives for the 1990's, Transaction Publishers, New Brunswick and London, 1994.

-, Liliana De Riz y Jorge Feldman, "El contexto y los dilemas de la concertación en la Argentina actual", en Mario
Dos Santos (comp.), Concertación político-socialy democratización, CIACso, Buenos Aircs, 1987.

-De Riz, Liliana, "Política y partidos. Ejercicio de análisis comparado: Argentina, Chilc, Brasil y Uruguay", en Marcelo Cavarozzi y Manuel Antonio Garreton (coords.), Muerte y resurrección. Los partidos políticos en el autoritartsmo y las transiciones del Cono Sur, FIACSO, Santiago, 1989.

- Retorno y derrumbe: el úlltmo gobiemo peronisla, Folios, México, 1981.

-Hirschman, Albert, "La matriz social y política de la inllación: claboración sobre la experiencia latinoamericana", en Albert Hirschman, De la economía a la política y más allá, Fondo de Cultura Económica, México, 1981.

-Mainwaring, Scott, Brazilian party, underdevelopment in comparative perspective, University of Notre Damc, The IIcllen Kellogg Institute for International Studies, 1990 (Working Paper No. 131).

-Morlino, Lconardo, "Partidos políticos y consolidación democrática en el sur de Furopa", en Jorge Bencdicto y liernando Reinares (comps.), Las transformaciones de la política, Nlianza, Madrid, 1992. 


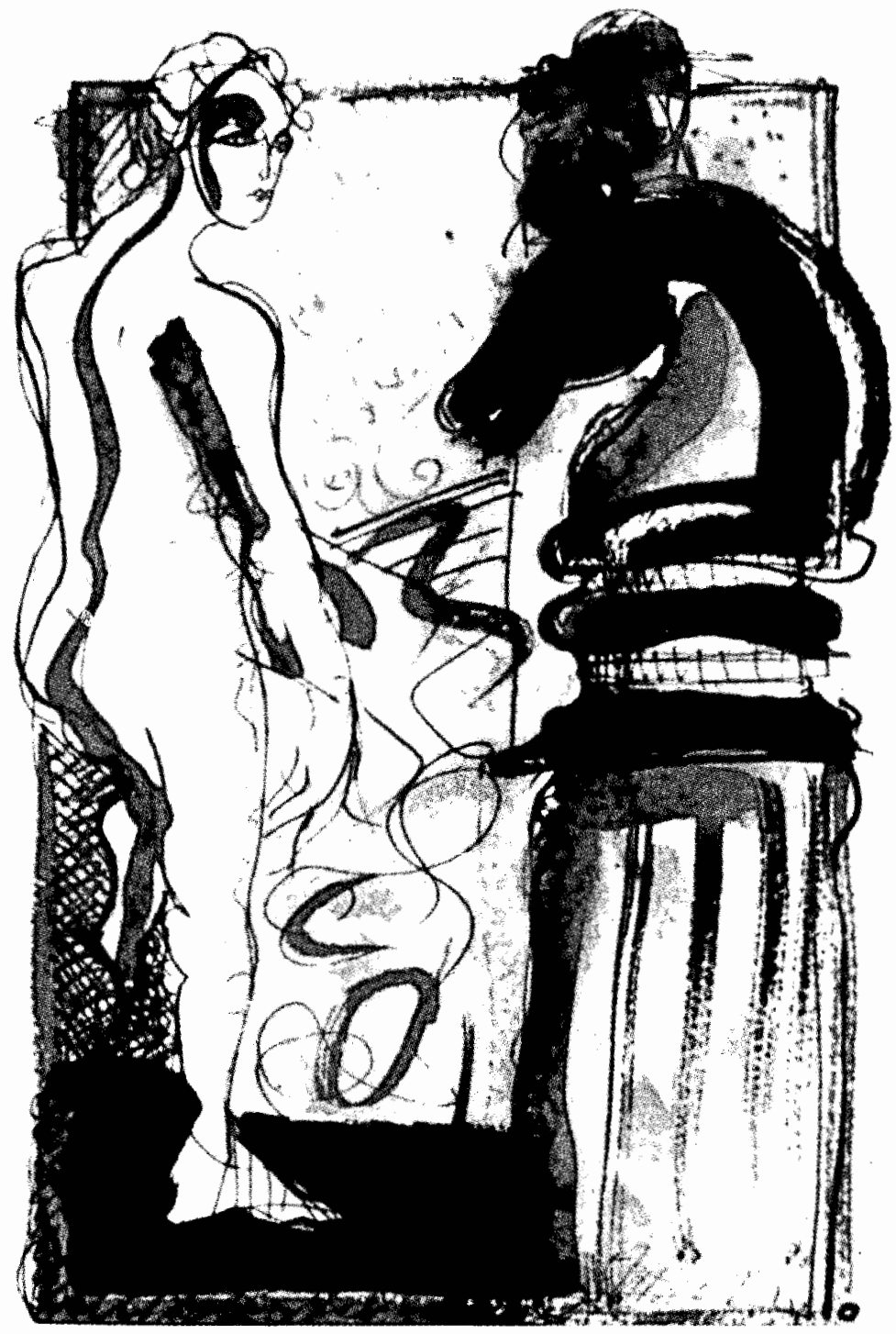

